\title{
¿Lichtenstein o Nyhus? Ese no es el dilema
}

\section{Lichtenstein or Nyhus? That is not the question}

\section{Correspondencia \\ Alessandra Cassana \\ ale_cass7@hotmail.com}

Recibido: 20/12/2016

Aprobado: 21/12/2016

Citar como: Cassana A. ¿Lichtenstein o Nyhus?: ese no es el dilema. Acta Med Peru. 2016;33(4):338-9

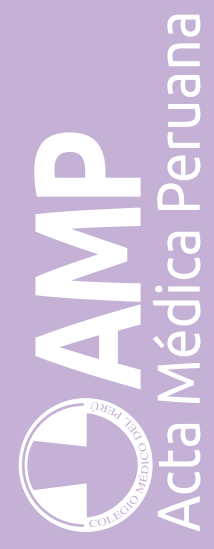

\author{
Alessandra Cassana $a^{1, a}$ \\ 1 Departamento de Cirugía General, Hospital Nacional Edgardo Rebagliati Martins. Lima, Perú. \\ a Médico Residente de Cirugía General
}

\section{Sr. Editor:}

El estudio de Granda y colaboradores ${ }^{[1]}$ aborda la discusión acerca de las complicaciones post operatorias de dos técnicas, Lichtenstein y Nyhus, en el manejo de las hernias inguinales en un hospital de nuestro país. En este interesante estudio existen algunas consideraciones que quisiera comentar y que deben ser abordadas con mayor rigor en el futuro.

Las complicaciones tardías, en especial las recurrencias, no solo dependen de la condición basal de los pacientes intervenidos o de la técnica quirúrgica utilizada ${ }^{[2]}$. Existen otras variables no medidas ni analizadas como el seguimiento de las indicaciones de recuperación post alta y el tipo de actividad física rutinaria que el paciente realiza en este periodo [3] que son probablemente factores también determinantes $y$, tanto temporal como causalmente, más relacionados a las recurrencias de hernias. En una población predominantemente masculina y de las fuerzas armadas, estas variables omitidas revisten mayor relevancia y su omisión en el análisis debe ser reconocida como seria limitación. Esta omisión es más seria dado que el tiempo exacto hasta las recurrencias exactas tampoco ha sido reportado o analizado. En futuros estudios, una forma de aproximar estas variables omitidas podría ser considerando indicadores indirectos como el rango militar, el tiempo en servicio o bien la posición o función exacta asignada dentro de la jerarquía militar. En general, la omisión de variables clave precisamente puede llevar a resultados con validez discutible.

Por su parte, las complicaciones tempranas podrían estar biológicamente relacionadas a la reciente cirugía aplicada; pero conceptualmente es muy discutible que dependan del tiempo de hospitalización (entendido como el tiempo transcurrido desde la cirugía hasta el alta, con o sin desarrollo de complicaciones interinas) a pesar de los hallazgos estadísticos reportados. Las complicaciones tempranas de tipo neuralgia o seroma son eventos que se desarrollan como consecuencia directa de las estructuras anatómicas afectadas durante el acto operatorio e independientemente de una corta o prolongada exposición temporal al entorno intrahospitalario a diferencia de, por ejemplo, la adquisición de infecciones intrahospitalarias. Y lo mismo aplica para las complicaciones tardías bajo el mismo argumento. La inclusión de variables predictoras de un evento en un modelo de regresión debe ir guiada, al menos parcialmente, por un criterio conceptual para llegar a resultados apropiados.

Precisamente, a propósito del tiempo de hospitalización como factor asociado, conceptualmente podría ser que el tiempo sea una consecuencia de la complicación temprana desarrollada (y no al revés como se plantea en el estudio), dado que uno de los factores que alarga el internamiento es, justamente, la aparición de complicaciones y su manejo requerido. Entonces, bajo el concepto 
de causalidad reversa ${ }^{[4,5]}$ es coherente encontrar que ese tiempo y las complicaciones tempranas estén asociadas; pero no en la dirección o por los argumentos planteados por los autores, quienes lo describen como un hallazgo original que bien vale la pena ser explorado en estudios subsiguientes.

En resumen, considero que el estudio es interesante y proporciona una descripción de la casuística operatoria de un hospital con población cautiva y única. Sin embargo, dos aspectos clave, las variables dependientes y el factor asociado, merecen ser revisados de forma importante para que los hallazgos descriptivos puedan ser complementados armoniosa y rigurosamente con una exploración de los factores asociados o predictores como la que pretendieron poner en práctica los investigadores.

\section{REFERENCIAS BIBLIOGRÁFICAS}

1. Granda AC, Correa-Tineo S, Quispe AM. Herniorrafía con la técnica de Lichtenstein versus Nyhus en el manejo de las hernias inguinales y sus complicaciones postoperatorias en un hospital del Perú. Acta Med Peru 2016;33(3):208-16

2. GopalSV, Warrier A. Recurrence after groin hernia repair-revisited. Int J Surg 2013;11(5):374-7.

3. Forbes J, Fry $\mathrm{N}$, Hwang $\mathrm{H}$, Karimuddin AA. Timing of return to work after hernia repair: Recommendations based on a literature review. BCMJ. 2012;54(7):341-5

4. Szklo M, Nieto FJ. Epidemiology: Beyond the Basics. Sudbury, MA: Jones and Bartlett Publishers; 2006.

5. Rothman KJ, Greenland S, Lash TL. Modern Epidemiology. 3rd ed. Philadelphia, PA: Wolters Kluwer/Lippincott Williams \& Wilkins; 2008.

\section{Las ediciones anteriores de Acta Médica Peruana están disponibles en:}

\section{www.redalyc.org}

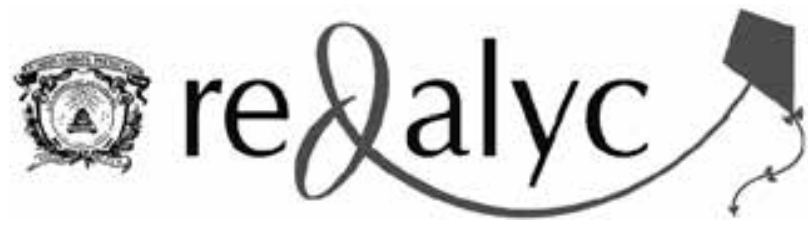

